\title{
Transcriptomic differences of genes in the avian target of rapamycin (avTOR) pathway in a divergent line of meat-type chickens selected for feed efficiency
}

\author{
J. Lee and S.E. Aggrey \\ NutriGenomics Laboratory, Department of Poultry Science, \\ University of Georgia, Athens, GA, USA \\ Corresponding author: S.E Aggrey \\ E-mail: saggrey@uga.edu
}

Genet. Mol. Res. 15 (2): gmr.15027120

Received June 30, 2015

Accepted September 4, 2015

Published June 30, 2016

DOI http://dx.doi.org/10.4238/gmr.15027120

\begin{abstract}
Avian target of rapamycin (avTOR) is a highly conserved serine-threonine kinase that serves as an intracellular energy and nutrient sensor and regulates cell division, growth, and apoptosis. The role of avTOR in mediating feed intake and growth in poultry is unknown. We studied avTOR signaling activities in duodenum and liver tissues at days 35 and 42 in chickens divergently selected for low (LRFI) or high (HRFI) residual feed intake. The differential expression of genes involved in the avTOR pathway was assayed using real-time polymerase chain reaction. In the duodenum, avTOR was up-regulated in the LRFI chickens at both time points as compared with the HRFI chickens. Other genes found to be differentially expressed at day 35 included v-akt murine thymoma viral oncogene homolog, eukaryotic translation elongation factor 2, eukaryotic translation initiation factor 4E binding protein 1, 3-phosphoinositide dependent protein kinase-1, ribosomal protein S6 kinase, $70 \mathrm{kDa}$, polypeptide 1 (RPS6KP1), avTOR associated protein, LST8 homolog, ghrelin, phosphoinositide-
\end{abstract}


3-kinase (PI3K), forkhead box O1, and p53 E3 ubiquitin protein ligase homolog (MDM2). At day 42, there was no change in the expression of the avTOR target RPS6KP1 or MDM2. In the liver, changes in the expression of components of the avTOR pathway primarily occurred at day 42, and differential gene expression suggests that avTOR complex 1 (avTORC1) affects feed efficiency at day 42. avTORC1 may be activated in the duodenum of feed-efficient birds to increase nutrient mobilization to other peripheral tissues. Furthermore, activation of avTOR in relation to feed efficiency may be tissue specific and may depend on the tissue's need for growth and nutrient transport. Genetic markers in key genes involved in the avTOR/PI3K pathway could be developed to improve feed efficiency in meat-type chickens.

Key words: Feed efficiency; avTOR; Gene expression; Chickens

\section{INTRODUCTION}

Target of rapamycin (TOR) is a highly conserved serine-threonine kinase, which serves as an intracellular ATP sensor (Dennis et al., 2001). TOR activity is regulated by hormones (including insulin/insulin-like growth factor), nutrients (including amino acids), and mitogens to stimulate protein synthesis and cell proliferation (Cota et al., 2006; Avruch et al., 2006). The TOR signaling pathway in the hypothalamus is activated under conditions of positive energy status, which are characterized by an elevated ATP/AMP ratio (Dennis et al., 2001). Upon depletion of ATP, activation of AMP-activated protein kinase, alpha 1 catalytic subunit (AMPK) inhibits TOR signaling, thereby suppressing protein synthesis and permitting AMPK to conserve cellular energy during a low energy state (Tokunaga et al., 2004). However, administration of specific nutrients, such as the branched chain amino acid leucine, also activates TOR signaling, leading to decreased food intake and body weight (Cota et al., 2006). TOR phosphorylates and regulates several downstream effectors that are involved in the control of protein translation, including p70 ribosomal S6 kinase (p70S6K), eukaryotic initiation factor 4E-binding protein 1 (4E-BP1), and eukaryotic initiation factor $4 \mathrm{G}$ (eIF4G) (Tokunaga et al., 2004). This effect is mediated through the tuberous sclerosis complex (TSC1/2) and Ras homolog enriched in brain (Rheb) (McManus and Alessi, 2002; Tokunaga et al., 2004). Thus, TOR coordinates intracellular energy and amino acid pathways.

There are two TOR complexes; TOR complex 1 (TORC1), which is responsible for nutrient sensing activities and is comprised of TOR, a G protein-subunit-like protein, avTOR associated protein, LST8 homolog (avLST8), and regulatory-associated protein of TOR1 (RAPTOR1); and TOR complex 2 (TORC2), which phosphorylates Akt protein kinase B and comprises TOR and rapamycin-insensitive companion of TOR (RICTOR), G $\beta$ L, and stress activated protein kinase interacting protein 1 (SIN1) (Yang et al., 2008). The raptor-TOR pathway regulates cell growth (accumulation of cell mass), and the two best characterized downstream effectors of TORC1 are S6K1 and eIF4E-BP1 (Yang and Guan, 2007). The rapamycin-insensitive rictor-TOR pathway regulates v-akt murine thymoma viral oncogene homolog (Akt)/protein kinase B (PKB), PKCa, and Rho/Rac to control cell survival, proliferation, metabolism, and the cytoskeleton. Akt/PKB is a key component of the 
insulin/PI3K signaling pathway, which modulates cell survival and proliferation (Frias et al., 2006). Huang et al. (2008) suggested that the TSC/2 complex positively regulates TORC2 independent of its GTPase-activating activity towards Rheb, and that the TSC1/2 complex can physically associate with TORC2, but not TORC1, demonstrating that the TSC1/2 complex inhibits TORC1 and activates TOR2, which promotes Akt activation through a different mechanism.

The TOR signaling pathway co-localizes with Agouti related peptide/Neuropeptide $\mathrm{Y}$ and proopiomelanocortin neurons in the arcuate hypothalamus; however, a significant increase in TOR signaling was observed in the liver and skeletal muscle of insulin-resistant obese rats fed a high fat diet (Khamzina et al., 2005) suggestive of peripheral cellular TOR signaling. Xu et al. (2009) further demonstrated that the TOR signaling system in gastric endocrine cells functions as a peripheral fuel sensor, which affects ghrelin expression to subsequently turn on hypothalamic neurons and thus regulate food intake. The product of the AMPK gene also functions in peripheral tissues such as liver and skeletal muscle to bring about changes in energy balance (Carling, 2005; Kahn et al., 2005). Thus, the coordinated regulation of hypothalamic AMPK and its downstream effects on metabolic pathways plays a critical role in the integration of hormonal and nutrient signaling that affects feed intake and whole-body energy homeostasis (Xue and Kahn, 2006). The objective of the present study was to investigate avian TOR (avTOR) signaling in peripheral tissues (duodenum and liver) in chickens, and to ascertain how the TOR signaling pathway affects feed efficiency.

\section{MATERIAL AND METHODS}

\section{Experimental population}

We used duodenum and liver tissues from a chicken population (Arkansas Random Bred, ARB) that is divergently selected for residual feed intake (RFI). The ARB was established in 1996 from poultry industry elite breeding lines (seven males and six females) and propagated yearly as a random mating population. The selection program was based on low or high daily 35-42 RFI breeding values for three generations. At days 35 and 42, four male chickens from each line were selected. There were 16 samples per tissue representing two lines and two ages. Tissues were taken from birds based on day 28-35 and 35-42 RFI. The RFI values of the birds used for the current study at day 28-35 were -108 and 486 for LRFI and HRFI, respectively, and for day 35-42 they were -202 and 324, respectively. Chicks were sexed at hatching, placed in pens with litter, and fed a ration containing $225 \mathrm{~g} / \mathrm{kg}$ protein, 52.8 $\mathrm{g} / \mathrm{kg}$ fat, $25.3 \mathrm{~g} / \mathrm{kg}$ fiber, $12.90 \mathrm{MJ} \mathrm{ME} / \mathrm{kg}, 9.5 \mathrm{~g} / \mathrm{kg} \mathrm{Ca}$, and $7.2 \mathrm{~g} / \mathrm{kg}$ total P $(4.5 \mathrm{~g} / \mathrm{kg}$ available P) until 18 days of age. Thereafter, they were fed $205 \mathrm{~g} / \mathrm{kg}$ protein, $57.6 \mathrm{~g} / \mathrm{kg}$ fat, $25.0 \mathrm{~g} / \mathrm{kg}$ fiber, $13.20 \mathrm{MJ} \mathrm{ME} / \mathrm{kg}, 9.0 \mathrm{~g} / \mathrm{kg} \mathrm{Ca}$, and $6.7 \mathrm{~g} / \mathrm{kg}$ total $\mathrm{P}(4.1 \mathrm{~g} / \mathrm{kg}$ available $\mathrm{P})$. At 28 days old, birds were fasted for $12 \mathrm{~h}$ and transferred to individual metabolism cages until 42 days of age. Birds were maintained under a $14 \mathrm{~h} \mathrm{~L}: 10 \mathrm{~h} \mathrm{D}$ light regimen. The feed intake, RFI, and body weight gain were obtained for days 28-35 and 35-42 and are presented in Table 1. Residual feed intake was calculated as the actual feed intake minus expected feed intake after correction for metabolic body weight (body weight ${ }^{0.75}$ ) and body weight gain (Aggrey et al., 2010). All animal protocols were approved by the Animal Care and Use committee of the University of Georgia. 
Table 1. Means $( \pm \mathrm{SE})$ of feed efficiency and physiological parameters in a chicken population divergently selected for low (LRFI) or high (HRFI) residual feed intake.

\begin{tabular}{l|c|c|c|c}
\hline Trait & Period (day) & LRFI $(\mathrm{N}=310)$ & HRFI $(\mathrm{N}=305)$ & Pr $>\mathrm{F}$ \\
\hline MBW & 28 & $171.43 \pm 1.15$ & $173.99 \pm 1.27$ & 0.1357 \\
\hline BWG & $28-35$ & $394.37 \pm 4.90$ & $420.89 \pm 5.42$ & 0.0003 \\
\hline FI & $28-35$ & $707.89 \pm 8.65$ & $803.15 \pm 9.58$ & $<0.0001$ \\
\hline RFI & $28-35$ & $-31.86 \pm 6.38$ & $32.33 \pm 7.07$ & $<0.0001$ \\
\hline FCR & $28-35$ & $1.80 \pm 0.02$ & $1.93 \pm 0.02$ & $<.0001$ \\
\hline MBW & 35 & $222.20 \pm 1.47$ & $227.81 \pm 1.62$ & 0.0103 \\
\hline BWG & $35-42$ & $376.39 \pm 4.72$ & $372.09 \pm 5.23$ & $<.5406$ \\
\hline FI & $35-42$ & $776.60 \pm 9.96$ & $886.72 \pm 10.91$ & $<0.0001$ \\
\hline RFI & $35-42$ & $-41.35 \pm 8.33$ & $54.80 \pm 9.22$ & $<0.0001$ \\
\hline FCR & $35-42$ & $2.13 \pm 0.04$ & $2.49 \pm 0.05$ & 0.0021 \\
\hline INS (pg/mL) & 35 & $0.78 \pm 0.03$ & $0.92 \pm 0.03$ & 0.0002 \\
\hline IGFI (ng/mL) & 35 & $36.76 \pm 0.86$ & $41.31 \pm 0.85$ & 0.0485 \\
\hline IGFII $(\mathrm{ng} / \mathrm{mL})$ & 35 & $101.26 \pm 4.23$ & $89.51 \pm 4.16$ & 0.4635 \\
\hline INS (pg/mL) & 42 & $1.19 \pm 0.03$ & $1.22 \pm 0.03$ & 0.3316 \\
\hline IGFI (ng/mL) & 42 & $39.62 \pm 0.78$ & $40.73 \pm 0.83$ & \\
\hline IGFII $(\mathrm{ng} / \mathrm{mL})$ & 42 & $61.86 \pm 2.37$ & $58.59 \pm 2.50$ & \\
\hline
\end{tabular}

${ }^{1} \mathrm{MBW}=$ metabolic body weight; $\mathrm{BWG}=$ body weight gain; FI = feed intake; FCR = feed conversion ratio; RFI $=$ residual feed intake; INS = insulin; IGF = insulin-like growth factor. ${ }^{2}$ All traits measured in $(\mathrm{g})$ except for FCR which was $(\mathrm{g} / \mathrm{g})$.

\section{RNA extraction and quantitative real time PCR analysis}

Total RNA was extracted from duodenum and liver tissues using TRIzol reagent (Invitrogen Corp., Carlsbad, CA, USA) according to the manufacturer instructions. The concentration of the extracted RNA was assessed by UV absorbance and the $\mathrm{OD}_{260 / 280}$ ratios for all samples were $>1.9$. RNA integrity was verified with a Bioanalyzer (Agilent Technologies, Palo Alto, CA, USA). All RNA samples displayed an RNA integrity number (RIN) of $\geq 9$. For cDNA synthesis, $2 \mu \mathrm{g}$ total RNA was reverse transcribed with high capacity cDNA reverse transcription kits according to the manufacturer protocol (Applied Biosystems, Carlsbad, CA, USA). Real-time PCR reactions were performed using StepOnePlus (Applied Biosystems). A sample of $0.5 \mu \mathrm{L}$ cDNA $(\sim 1.25 \mathrm{ng} / \mu \mathrm{L}$ in final solution) served as a template in a $20-\mu \mathrm{L}$ PCR mixture containing $0.3 \mu \mathrm{L}$ each of forward and reverse primers from $10 \mu \mathrm{M}$ stocks $(0.15 \mu \mathrm{M}$ in final solution) and $2 \mathrm{X}$ Fast SYBR Green Master Mix (Applied Biosystems, Carlsbad, CA). The PCR conditions were $95^{\circ} \mathrm{C}$ for $20 \mathrm{~s}$, followed by 40 cycles of $95^{\circ} \mathrm{C}$ for $3 \mathrm{~s}$ and $60^{\circ} \mathrm{C}$ for 30 $\mathrm{s}$. In addition, at the end of each reaction, melting temperature curve analysis was performed. The gene expression differences between the LRFI and HRFI for v-akt murine thymoma viral oncogene homolog AKT1, AKT2, AKT3, eukaryotic translation elongation factor 2 (EEF2), eukaryotic translation initiation factor 4E binding protein 1(EIF4EBP1), hypoxia inducible factor 1 (HIF1A), insulin-like growth factor 1 (IGF1), avTOR, 3-phosphoinositide dependent protein kinase-1 (PDPK1), RICTOR, ribosomal protein S6 (RPS6), ribosomal protein S6 kinase, 70kDa, polypeptide 1 (RPS6KP1), RAPTOR, signal transducer and activator of transcription 3 (STAT3), vascular endothelial growth factor A (VEGFA), insulin receptor substrate 1 (IRS1), insulin (INS), avTOR associated protein, avLST8, AMPK, ghrelin (GHRL), cyclin D1 (CCND), phosphoinositide-3-kinase (PI3K), forkhead box O1 (FOXO1), p53 E3 ubiquitin protein ligase homolog (MDM2) and Glycogen synthase 3 kinase beta (GSK3 $\beta$ ) were analyzed according to the $2^{-\Delta \Delta C t}$ method (Livak and Schmittgen 2001) and were normalized to $\beta$-actin expression in each sample. We first tested the efficacy of glyceraldehyde 3 phosphate, hypoxanthine-guanine phosphoribosyltransferase 1 , and $\beta$-actin 
for use as internal standards, and ascertained that $\beta$-actin was more appropriate for the current study. Differential gene expression was expressed as LRFI/HRFI. Statistical differences in gene expression between lines were determined using PROC GLM (SAS Institute, 2000) and P£0.05 was considered as significant. The NCBI accession No., forward and reverse primers, and annealing temperatures are provided in $\underline{\text { S1 Table. }}$.

\section{Hormonal levels}

About $4 \mathrm{~mL}$ of blood was collected from each bird on days 35 and 42 using ethylene diamine tetra acetic acid as an anticoagulant. The blood samples were centrifuged for $10 \mathrm{~min}$ at $503 \mathrm{~g}$, and the plasma was separated and stored frozen at $-20^{\circ} \mathrm{C}$. The frozen plasma was analyzed in duplicate for IGF-I, IGF-II, and insulin using homologous hormone assays. To avoid interassay variation, all samples were analyzed in the same assay. Double-antibody radioimmunoassay was used to determine plasma concentrations of IGF-I with an intraassay coefficient of variation (CV) of 2.8\% (McMurtry et al., 1994), chicken IGF-II with an intraassay CV of 3.7\% (McMurtry et al., 1998), and insulin with an intraassay CV of 2.2\% (McMurtry et al., 1983).

\section{RESULTS}

The feed efficiency and physiological parameters of the LRFI and HRFI lines are provided in Table 1. Divergent selection was based on the day 35-42 RFI. The LRFI line improved feed efficiency by reducing feed intake (FI) compared to the feed inefficient HRFI line during the same age period. However, for the same response at day 28-35, the LRFI line improved feed efficiency by reducing both FI and BWG. Insulin and IGFI levels were lower $(\mathrm{P} \leq 0.01)$, and IGFII was higher $(\mathrm{P} \leq 0.05)$ in the LRFI line at day 35 compared to the HRFI line. There were no differences in insulin, IGFI, and IGFII levels between the two divergently selected lines at day 42. Insulin levels were increased in both lines from day 35 to 42 and the relative increase was about two-fold higher in the LRFI line compared to that in the HRFI line. While there was no significant change in the IGFI level in both lines from day 35 to 42 , there was a significant decline in IGFII levels from day 35 to 42 .

The relative mRNA levels of genes involved in the avTOR pathway in duodenum and liver tissues are presented in Tables 2 and 3, respectively. The results suggest that mRNA expression is affected by both age and peripheral tissue. Differences in gene expression in the duodenum at day 35 are shown in Figure 1. The AKT3, avLST8, AMPK, GHRL and MDM2 genes were up-regulated in HRFI chickens in both duodenum and liver tissues at day 35. However, at day 42, AKT3, and avLST8 were down-regulated in HFRI chickens in both tissues, whereas AMPK and GHRL were down-regulated only in the liver and not in the duodenum. Phosphoinositide-3-kinase (PI3K), which is upstream the avTOR complex, was down-regulated only in LRFI chickens at day 35 in the duodenum but not in the liver.

The avTOR gene was up-regulated in the duodenum of LRFI chickens at both ages, but only at day 42 in the liver. In the duodenum, raptor independent companion of RICTOR and PDPK1 were down-regulated in LRFI chickens at day 35 and up-regulated at day 42; however, in the liver, PDPK1 was up-regulated only at day 42. Among the genes downstream of TORC1 and TORC2, EEF2, EIF4EBP1 and FOXO1 were down-regulated in LRFI chickens at day 35, but were up-regulated at day 42 in the duodenum. In the liver, EEF2, EIF4EBP1, and FOXO1 were not differentially expressed at day 35, but were up-regulated in LRFI chickens at day 42 . 
Table 2. mRNA expression of genes $( \pm \mathrm{SE})$ of the avTOR pathway in the duodenum of chickens divergently selected for residual feed efficiency.

\begin{tabular}{l|l|c|c}
\hline Gene & & \multicolumn{2}{|c}{ Fold change } \\
\hline Symbol & Gene name & Day 35 & Day 42 \\
\hline AKT1 & v-akt murine thymoma viral oncogene homolog 1 & $1.35 \pm 0.09^{* *}$ & $1.39 \pm 0.05^{* * *}$ \\
\hline AKT2 & v-akt murine thymoma viral oncogene homolog 2 & $-1.28 \pm 0.05^{*}$ & $1.20 \pm 0.18$ \\
\hline AKT3 & v-akt murine thymoma viral oncogene homolog 3 & $-1.72 \pm 0.04^{* *}$ & $1.73 \pm 0.17^{* *}$ \\
\hline EEF2 & Eukaryotic translation elongation factor 2 & $-1.56 \pm 0.07^{*}$ & $1.37 \pm 0.27^{*}$ \\
\hline EIF4EBP1 & Eukaryotic translation initiation factor 4E binding protein 1 & $-2.17 \pm 0.01^{* * *}$ & $1.44 \pm 0.25^{*}$ \\
\hline HIF1A & Hypoxia inducible factor 1 & $1.03 \pm 0.07$ & $1.49 \pm 0.09^{*}$ \\
\hline IGF1 & Insulin-like growth factor 1 & $1.44 \pm 0.05^{* * *}$ & $1.34 \pm 0.19^{*}$ \\
\hline avTOR & Avian target of rapamycin & $1.21 \pm 0.08^{*}$ & $1.35 \pm 0.13^{*}$ \\
\hline PDPK1 & 3-phosphoinositide dependent protein kinase-1 & $-1.39 \pm 0.04^{* * *}$ & $1.40 \pm 0.07^{*}$ \\
\hline RICTOR & RPTOR independent companion of MTOR, complex 2 & $-1.25 \pm 0.05^{*}$ & $1.83 \pm 0.21^{* *}$ \\
\hline RPS6 & Ribosomal protein S6 & $-1.45 \pm 0.06^{*}$ & $1.21 \pm 0.14$ \\
\hline RPS6KP1 & Ribosomal protein S6 kinase, 70kDa, polypeptide 1 & $-1.56 \pm 0.04^{* *}$ & $1.12 \pm 0.09$ \\
\hline RAPTOR & Regulatory associated protein of MTOR, complex 1 & $-1.04 \pm 0.06$ & $1.43 \pm 0.10^{*}$ \\
\hline STAT3 & Signal transducer and activator of transcription 3 & $-1.07 \pm 0.09$ & $-1.08 \pm 0.17$ \\
\hline VEGFA & Vascular endothelial growth factor A & $1.09 \pm 0.04$ & $1.26 \pm 0.03^{*}$ \\
\hline IRS1 & Insulin receptor substrate 1 & $1.12 \pm 0.19$ & $1.31 \pm 0.2 *^{*}$ \\
\hline INS & Insulin & $-2.70 \pm 0.05^{*}$ & $3.02 \pm 0.54^{* *}$ \\
\hline avLST8 & avTOR associated protein, LST8 homolog & $-1.30 \pm 0.02^{*}$ & $1.30 \pm 0.09^{*}$ \\
\hline AMPK & AMP-activated protein kinase, alpha 1 catalytic subunit & $-1.25 \pm 0.03^{*}$ & $1.17 \pm 0.09$ \\
\hline GHRL & Ghrelin & $-2.70 \pm 0.04^{*}$ & $1.06 \pm 0.19$ \\
\hline CCND & Cyclin D1 & $-1.10 \pm 0.06$ & $1.20 \pm 0.04$ \\
\hline PI3K & Phosphoinositide-3-kinase & $-1.25 \pm 0.05^{*}$ & $1.12 \pm 0.7$ \\
\hline FOXO1 & Forkhead box O1 & $-1.61 \pm 0.05^{*}$ & $1.61 \pm 0.18^{* *}$ \\
\hline MDM2 & p53 E3 ubiquitin protein ligase homolog & $-1.33 \pm 0.02^{*}$ & $1.11 \pm 0.08$ \\
\hline GSK3 3 & Glycogen synthase 3 kinase beta & $-1.04 \pm 0.12$ & $1.24 \pm 0.12^{*}$ \\
\hline$*$ P 0 & & &
\end{tabular}

$* \mathrm{P} \leq 0.05 ; * * \mathrm{P} \leq 0.01 ; * * * \mathrm{P} \leq 0.001$.

Table 3. mRNA expression of genes $( \pm \mathrm{SE})$ in the avTOR pathway in the liver of chickens divergently selected for residual feed efficiency.

\begin{tabular}{l|l|c|c}
\hline Gene & & \multicolumn{2}{c}{ Fold change } \\
\hline Symbol & Gene name & Day 35 & Day 42 \\
\hline AKT1 & v-akt murine thymoma viral oncogene homolog 1 & $1.05 \pm 0.12$ & $1.16 \pm 0.10$ \\
\hline AKT2 & v-akt murine thymoma viral oncogene homolog 2 & $-1.01 \pm 0.05$ & $1.68 \pm 0.12^{*}$ \\
\hline AKT3 & v-akt murine thymoma viral oncogene homolog 3 & $-1.32 \pm 0.02^{*}$ & $1.29 \pm 0.05^{*}$ \\
\hline EEF2 & Eukaryotic translation elongation factor 2 & $1.04 \pm 0.08$ & $1.32 \pm 0.10^{*}$ \\
\hline EIF4EBP1 & Eukaryotic translation initiation factor 4E binding protein 1 & $-1.05 \pm 0.08$ & $1.39 \pm 0.10^{*}$ \\
\hline HIF1A & Hypoxia inducible factor 1 & $1.01 \pm 0.07$ & $1.18 \pm 0.08^{*}$ \\
\hline IGF1 & Insulin-like growth factor 1 & $-1.30 \pm 0.09^{*}$ & $-1.27 \pm 0.09^{*}$ \\
\hline avTOR & Avian target of rapamycin & $1.01 \pm 0.03$ & $1.22 \pm 0.04^{*}$ \\
\hline PDPK1 & 3-phosphoinositide dependent protein kinase-1 & $1.09 \pm 0.10$ & $1.30 \pm 0.07^{*}$ \\
\hline RICTOR & RPTOR independent companion of MTOR, complex 2 & $-1.10 \pm 0.10$ & $-1.14 \pm 0.10$ \\
\hline RPS6 & Ribosomal protein S6 & $1.18 \pm 0.08$ & $1.15 \pm 0.10$ \\
\hline RPS6KP1 & Ribosomal protein S6 kinase, 70kDa, polypeptide 1 & $1.39 \pm 0.11^{* *}$ \\
\hline RAPTOR & Regulatory associated protein of MTOR, complex 1 & $1.01 \pm 0.03$ & $1.13 \pm 0.04$ \\
\hline STAT3 & Signal transducer and activator of transcription 3 & $1.10 \pm 0.03$ & $1.75 \pm 0.14^{* *}$ \\
\hline VEGFA & Vascular endothelial growth factor A & $-1.32 \pm 0.05^{* *}$ & $1.20 \pm 0.21$ \\
\hline IRS1 & Insulin receptor substrate 1 & $-1.56 \pm 0.03^{*}$ & $-1.10 \pm 0.09$ \\
\hline INS & Insulin & $-1.33 \pm 0.11^{*}$ & $1.28 \pm 0.08^{* *}$ \\
\hline avLST8 & avTOR associated protein, LST8 homolog & $-1.02 \pm 0.14$ & $1.28 \pm 0.06^{*}$ \\
\hline AMPK & AMP-activated protein kinase & $-1.39 \pm 0.04^{*}$ & $1.33 \pm 0.05^{* *}$ \\
\hline GHRL & Ghrelin & $-1.33 \pm 0.03^{*}$ & $1.62 \pm 0.15^{* *}$ \\
\hline CCND & Cyclin D1 & $-1.69 \pm 0.05^{*}$ & $1.12 \pm 0.18$ \\
\hline PI3K & Phosphoinositide-3-kinase & $1.09 \pm 0.02$ & $1.10 \pm 0.02$ \\
\hline FOXO1 & forkhead box O1 & $1.08 \pm 0.05$ & $1.44 \pm 0.09^{* *}$ \\
\hline MDM2 & p53 E3 ubiquitin protein ligase homolog & $1.19 \pm 0.04$ & $1.11 \pm 0.02$ \\
\hline GSK $\beta$ & Glycogen synthase kinase 3 beta & $-1.39 \pm 0.02^{*}$ & $1.10 \pm 0.06$ \\
\hline
\end{tabular}

$* \mathrm{P} \leq 0.05 ; * * \mathrm{P} \leq 0.01$ 


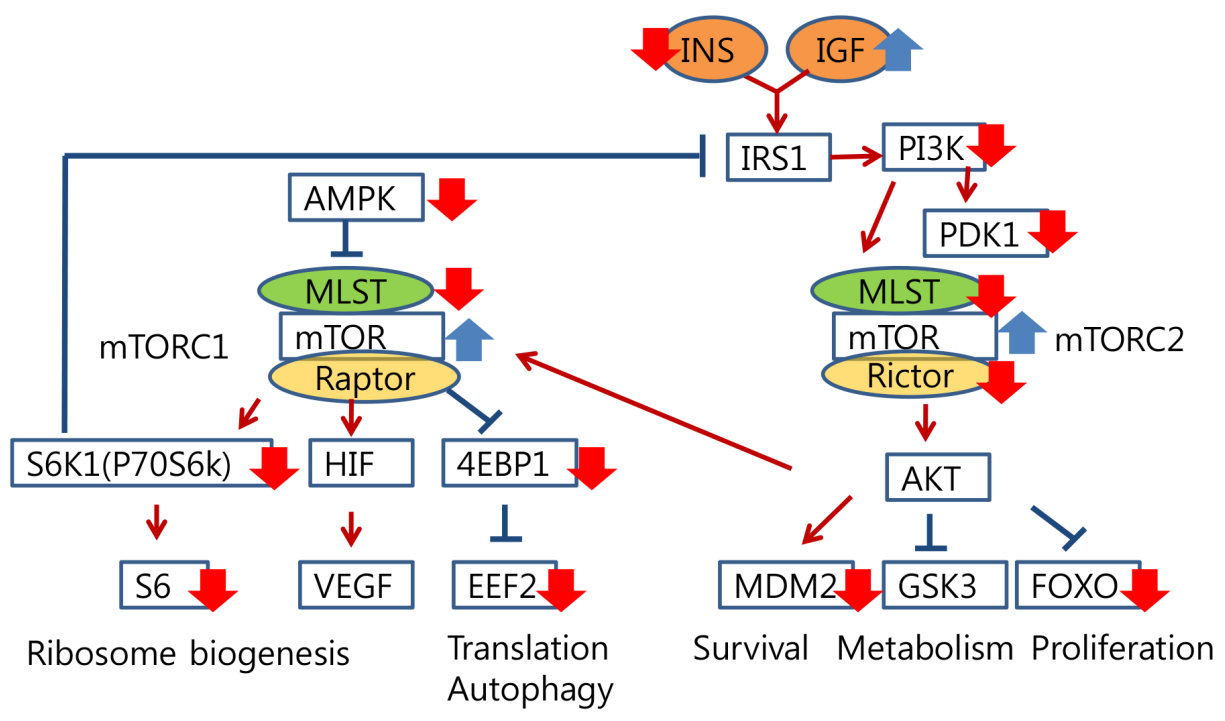

Figure 1. Relative gene expression at day 35 in the duodenum of chickens selected for low (LRFI) or high (HRFI) residual feed intake. Upwards pointing arrow $=$ up-regulation in LRFI/HRFI lines; downwards pointing arrow $=$ down-regulation in LRFI/HRFI lines. INS = insulin; IGF = insulin-like growth factor; AMPK = AMP-activated protein kinase; avLST8 homolog = avTOR associated protein; avTOR = avian target of rapamycin; avTORC1 = avTOR complex 1; avTORC2 = avTOR complex 2; S6K1 = ribosomal protein S6 kinase 1; HIF = hypoxia inducible factor; 4EBP1 = eukaryotic translation initiation factor 4; S6 = ribosomal protein S6; VEGF = vascular endothelial growth factor; EEF2 = eukaryotic translation elongation factor 2; IRS1 = insulin receptor substrate 1; PI3K = phosphoinositide 3 kinase; PDK1 = 3-phosphoinositide dependent protein kinase 1; Raptor $=$ regulatory associated protein of avTORC1; Rictor $=$ raptor independent companion of avTORC2; AKT $=$ v-akt murine thymoma viral oncogene homolog; MDM2 = p53 E3 ubiquitin protein ligase homolog; GSK3 = glycogen synthase kinase 3 beta; $\mathrm{FOXO}=$ forkhead box $\mathrm{O}$.

\section{DISCUSSION}

AMPK is an evolutionary conserved enzyme that acts as a sensor of cellular energy status (Kahn et al., 2005) and modulates energy balance at the whole body level by regulating feed intake and energy expenditure. In the present study, AMPK was found to be downregulated in the LRFI chicken line at day 35 in both the duodenum and the liver. However, in the duodenum, the down-regulation of AMPK at day 35 coincided with an up-regulation of avTOR in the LRFI line. In the liver, down-regulation of AMPK did not lead to changes in avTOR expression. avTOR regulation may be tissue specific (Kola et al., 2005) or it may be affected by upstream regulators other than AMPK. Anthony et al. (2002) demonstrated that infusion of both leucine and insulin can enhance TOR signaling. The LRFI chickens retained more nitrogen per feed intake than the HRFI chickens did (Aggrey et al., 2014) and may require a much more efficient system for transporting amino than is needed by the HRFL chickens. The avTORC1 complex comprises avTOR, avLST8, and raptor, and the raptor-TOR interaction regulates TORC1 activity (Wullschleger et al., 2006). Changes in avTOR and raptor gene expression in the duodenum of LRFI chicken at day 35 may affect the avTORC1 effectors, S6K1 and 4E-BP1 (Hay and Sonenberg, 2004). The EEF2, EIF4EBP1, RPS6, and RPS6KP1 
genes were all down-regulated in the duodenum at day 35 . The down-regulation of the effector genes avTORC1 in the LRFI line cannot be attributed to amino acid deprivation, as these birds were provided feed ad libitum. Even though the avTOR gene was down-regulated in the HRFI line, most of the downstream genes were up-regulated. In the duodenum of the divergent lines at day 35, signals upstream of the avTOR gene may be responsible for the altered expression of the downstream gene avTOR. Nawroth et al. (2011) provided evidence of TOR-independent but PI3K-dependent regulation of 4E-BP1. Thus, the TOR signally pathway can sense energy levels either directly through avTOR or indirectly through AMPK (Um et al., 2006).

The TOR pathway responds to growth factors through the PI3K pathway, and these two pathways are linked via the tuberous sclerosis proteins TSC1 and TSC2 (Richardson et al., 2004; Um et al., 2006). Here, PI3K and the stress induced HIF1A genes were downregulated in the duodenum of LRFI chickens at day 35. Furthermore, the plasma insulin, IGFI, and IGFII levels were significantly lower in the LRFI line compared to HRFI at day 35. The different levels of these growth factors could trigger the PI3K signaling pathway to directly or indirectly affect avTORC1. Both insulin and IGFI have been shown to mediate PI3K activation and have a negative feedback relationship with S6K (Courtney et al., 2010). Down-regulation of RPS6 and RPS6KP1 in the duodenum at day 35 suggests that these genes may be under the regulation of PI3K rather than avTORC1 in LRFI.

Cota et al. (2007) showed that TORC1 activation in the hypothalamus suppresses food intake, thereby creating a systemic negative feedback loop to maintain nutrient homeostasis, and TORC1 also increases nutrient mobilization into peripheral tissues through enhanced lipid storage in adipose tissue. It is possible that TORC1 activation in the duodenum may act synergistically with its counterpart in the hypothalamus to suppress feed intake and consequentially increase nutrient mobilization to other peripheral tissues. Coincidentally, the FOXO1 and MDM2 genes, which are associated with cell division, growth, proliferation, and apoptosis (Datta et al., 1997; Brunet et al., 1999; Huang and Tindall, 2006; Feng, 2010), were also found to be down-regulated in the duodenum of LRFI at day 35. avTORC2 appears to be active in the duodenum at day 42, whereas avTOR, AKT1, AKT3, RICTOR, HIF1A, EEF2, EIF4EBP1, PDPK1, RICTOR, FOXO1, GSK3 $\beta$, avLST8, VEGFA and IRS1 were all upregulated in the line LRFI compared to HRFI. Depending on the tissue need for growth and/ or nutrient transport, avTOR signaling may be activated to meet those challenges, which may reflect changes in gene expression in the feed efficiency lines.

Changes in plasma IGFI levels were observed between the LRFI and HRFI lines at day 35 but not at day 42. TORC2 phosphorylates and activates AKT (Sarbassov et al., 2004), and AKT regulates cell proliferation, survival, metabolism, and transcription (Jacinto et al., 2004). It has been suggested that growth factors may regulate TORC2 (Sarbassov et al., 2004; Jacinto et al., 2004), but whether this involves the same signaling cascades that regulate TORC1 is not yet known. It appears that in the LRFI line, TORC1 is activated at day 35, whereas AKT/ TORC2 is activated at day 42 to promote cell survival and stabilization.

VEGFA was up-regulated in the LRFI line at day 42 in the duodenum. VEGFA is a growth factor involved in angiogenesis, vasculogenesis, and endothelial cell growth, it also induces endothelial cell proliferation, promotes cell migration, and inhibits apoptosis. Brugarolas et al. (2003) demonstrated that TSC2 regulates VEGF through TOR-dependent and -independent pathways, and that the TOR independent pathway of VEGF may involve chromatin remodeling. VEGF and insulin, which both promote angiogenesis, induce AKTdependent signals (Shiojima and Walsh, 2002). Up-regulation of VEGFA in the LRFI line 
could support active nutrient transport to other peripheral tissues.

In the liver at day 35 , both avTOR complexes were up-regulated; however, IGFI, GHRL, HIF1A, and MDM2 were down-regulated in the LRFI line and there was no difference in the expression of avTOR between the LRFI and HRFI lines. Kola et al. (2005) showed that while ghrelin stimulated AMPK activity in the hypothalamus and heart, it inhibited AMPK in liver and adipose tissue. Since changes in the expression of AMPK and GHRL in liver occur in the same direction at days 35 and 42, it is possible that these act in the same way in relation to feed efficiency in chickens. At day 42, avTOR was up-regulated in the liver of LRFI chickens. This may be due to up-stream effectors like AKT2, AKT3, and PDPK1 and downstream effectors such as RPS6KP1, which were also up-regulated. Notably in the liver at day 42, STAT3 and FOXO1 were up-regulated in the LRFI line. STAT3 is a transcription factor that is usually activated in response to cytokines and growth factors, such as fibroblast growth factors and epidermal growth factors (Zhang et al., 2005). STAT3 mediates the expression of a variety of genes in response to cell stimuli and is involved in cell growth and division, cell movement, and apoptosis (Hirano et al., 2000).

There were several limitations to the current study. For example, differential gene expression between tissues and over age should be considered as well as the differences between divergent lines. However, taken together, these data suggest the potential involvement of the avTOR/PI3K pathway in the determination of feed efficiency in chickens. Genes in these pathways are intimately involved in cell growth, autophagy, survival, and metabolism and can affect both feed intake and growth; however, a role for other signaling pathways cannot be excluded. Genetic markers in key genes of the avTOR/PI3K pathways could be developed to improve feed efficiency in meat-type chickens. The genetic interrelationship between body weight gain, feed intake, and feed efficiency in meat-type chickens have been elucidated (Aggrey et al., 2010). Selection of RFI at day 35-42 in the population used was found to improve feed efficiency at day 28-35 by reducing feed intake and, to a lesser extent, body weight gain, and also improved feed efficiency at day 35-42 by reducing feed intake without changes to body weight gain (Table 1). The genetic interrelationships of feed efficiency parameters at day 28-35 differ from those at day 35-42, which could explain the changes in gene expression between two age periods.

\section{Conflicts of interest}

The authors declare no conflict of interest.

\section{ACKNOWLEDGMENTS}

Research supported by USDA NRI grant 2009-35205-05208 and Georgia Food Industry Partnership grant 10.26KR696-110. We appreciate the assistance of Christopher McKenzie of the Poultry Research Center of University of Georgia.

\section{REFERENCES}

Aggrey SE, Karnuah AB, Sebastian B and Anthony NB (2010). Genetic properties of feed efficiency parameters in meattype chickens. Genet. Sel. Evol. 42: 25. http://dx.doi.org/10.1186/1297-9686-42-25

Aggrey SE, Lee J, Karnuah AB and Rekaya R (2014). Transcriptomic analysis of genes in the nitrogen recycling pathway 
of meat-type chickens divergently selected for feed efficiency. Anim. Genet. 45: 215-222. http://dx.doi.org/10.1111/ age. 12098

Anthony JC, Reiter AK, Anthony TG, Crozier SJ, et al. (2002). Orally administered leucine enhances protein synthesis in skeletal muscle of diabetic rats in the absence of increases in 4E-BP1 or S6K1 phosphorylation. Diabetes 51: 928936. http://dx.doi.org/10.2337/diabetes.51.4.928

Avruch J, Hara K, Lin Y, Liu M, et al. (2006). Insulin and amino-acid regulation of mTOR signaling and kinase activity through the Rheb GTPase. Oncogene 25: 6361-6372. http://dx.doi.org/10.1038/sj.onc.1209882

Brugarolas JB, Vazquez F, Reddy A, Sellers WR, et al. (2003). TSC2 regulates VEGF through mTOR-dependent and -independent pathways. Cancer Cell 4: 147-158. http://dx.doi.org/10.1016/S1535-6108(03)00187-9

Brunet A, Bonni A, Zigmond MJ, Lin MZ, et al. (1999). Akt promotes cell survival by phosphorylating and inhibiting a Forkhead transcription factor. Cell 96: 857-868. http://dx.doi.org/10.1016/S0092-8674(00)80595-4

Carling D (2005). AMP-activated protein kinase: balancing the scales. Biochimie 87: 87-91. http://dx.doi.org/10.1016/j. biochi.2004.10.017

Cota D, Proulx K, Smith KA, Kozma SC, et al. (2006). Hypothalamic mTOR signaling regulates food intake. Science 312: 927-930. http://dx.doi.org/10.1126/science.1124147

Cota D, Proulx K and Seeley RJ (2007). The role of CNS fuel sensing in energy and glucose regulation. Gastroenterology 132: 2158-2168. http://dx.doi.org/10.1053/j.gastro.2007.03.049

Courtney KD, Corcoran RB and Engelman JA (2010). The PI3K pathway as drug target in human cancer. J. Clin. Oncol. 28: 1075-1083. http://dx.doi.org/10.1200/JCO.2009.25.3641

Datta SR, Dudek H, Tao X, Masters S, et al. (1997). Akt phosphorylation of BAD couples survival signals to the cellintrinsic death machinery. Cell 91: 231-241. http://dx.doi.org/10.1016/S0092-8674(00)80405-5

Dennis PB, Jaeschke A, Saitoh M, Fowler B, et al. (2001). Mammalian TOR: a homeostatic ATP sensor. Science 294: 1102-1105. http://dx.doi.org/10.1126/science.1063518

Feng Z (2010). p53 regulation of the IGF-1/AKT/mTOR pathways and the endosomal compartment. Cold Spring Harb. Perspect. Biol. 2: a001057. http://dx.doi.org/10.1101/cshperspect.a001057

Frias MA, Thoreen CC, Jaffe JD, Schroder W, et al. (2006). mSin1 is necessary for Akt/PKB phosphorylation, and its isoforms define three distinct mTORC2s. Curr. Biol. 16: 1865-1870. http://dx.doi.org/10.1016/j.cub.2006.08.001

Hay N and Sonenberg N (2004). Upstream and downstream of mTOR. Genes Dev. 18: 1926-1945. http://dx.doi. org/10.1101/gad.1212704

Hirano T, Ishihara K and Hibi M (2000). Roles of STAT3 in mediating the cell growth, differentiation and survival signals relayed through the IL-6 family of cytokine receptors. Oncogene 19: 2548-2556. http://dx.doi.org/10.1038/ sj.onc. 1203551

Huang H and Tindall DJ (2006). FOXO factors: a matter of life and death. Future Oncol. 2: 83-89. http://dx.doi. org/10.2217/14796694.2.1.83

Huang J, Dibble CC, Matsuzaki M and Manning BD (2008). The TSC1-TSC2 complex is required for proper activation of mTOR complex 2. Mol. Cell. Biol. 28: 4104-4115. http://dx.doi.org/10.1128/MCB.00289-08

Jacinto E, Loewith R, Schmidt A, Lin S, et al. (2004). Mammalian TOR complex 2 controls the actin cytoskeleton and is rapamycin insensitive. Nat. Cell Biol. 6: 1122-1128. http://dx.doi.org/10.1038/ncb1183

Kahn BB, Alquier T, Carling D and Hardie DG (2005). AMP-activated protein kinase: ancient energy gauge provides clues to modern understanding of metabolism. Cell Metab. 1: 15-25. http://dx.doi.org/10.1016/j.cmet.2004.12.003

Khamzina L, Veilleux A, Bergeron S and Marette A (2005). Increased activation of the mammalian target of rapamycin pathway in liver and skeletal muscle of obese rats: possible involvement in obesity-linked insulin resistance. Endocrinology 146: 1473-1481. http://dx.doi.org/10.1210/en.2004-0921

Kola B, Hubina E, Tucci SA, Kirkham TC, et al. (2005). Cannabinoids and ghrelin have both central and peripheral metabolic and cardiac effects via AMP-activated protein kinase. J. Biol. Chem. 280: 25196-25201. http://dx.doi. org/10.1074/jbc.C500175200

Livak KJ and Schmittgen TD (2001). Analysis of relative gene expression data using real-time quantitative PCR and the 2(-Delta Delta C(T)) Method. Methods 25: 402-408. http://dx.doi.org/10.1006/meth.2001.1262

McManus EJ and Alessi DR (2002). TSC1-TSC2: a complex tale of PKB-mediated S6K regulation. Nat. Cell Biol. 4: E214-E216. http://dx.doi.org/10.1038/ncb0902-e214

McMurtry JP, Rosebrough RW and Steele NC (1983). A homologous radioimmunoassay for chicken insulin. Poult. Sci. 62: 697-701. http://dx.doi.org/10.3382/ps.0620697

McMurtry JP, Francis GL, Upton FZ, Rosselot G, et al. (1994). Developmental changes in chicken and turkey insulin-like growth factor-I (IGF-I) studied with a homologous radioimmunoassay for chicken IGF-I. J. Endocrinol. 142: 225234. http://dx.doi.org/10.1677/joe.0.1420225 
McMurtry JP, Rosebrough RW, Brocht DM, Francis GL, et al. (1998). Assessment of developmental changes in chicken and turkey insulin-like growth factor-II by homologous radioimmunoassay. J. Endocrinol. 157: 463-473. http:// dx.doi.org/10.1677/joe. 0.1570463

Nawroth R, Stellwagen F, Schulz WA, Stoehr R, et al. (2011). S6K1 and 4E-BP1 are independent regulated and control cellular growth in bladder cancer. PLoS One 6: e27509. http://dx.doi.org/10.1371/journal.pone.0027509

Richardson CJ, Schalm SS and Blenis J (2004). PI3-kinase and TOR: PIKTORing cell growth. Semin. Cell Dev. Biol. 15: 147-159. http://dx.doi.org/10.1016/j.semcdb.2003.12.023

Sarbassov DD, Ali SM, Kim DH, Guertin DA, et al. (2004). Rictor, a novel binding partner of mTOR, defines a rapamycininsensitive and raptor-independent pathway that regulates the cytoskeleton. Curr. Biol. 14: 1296-1302. http://dx.doi. org/10.1016/j.cub.2004.06.054

SAS Institute (2000). SAS/STAT User's Guide. Version 8 Ed. SAS Inst. Inc., Cary, North Carolina.

Shiojima I and Walsh K (2002). Role of Akt signaling in vascular homeostasis and angiogenesis. Circ. Res. 90: $1243-$ 1250. http://dx.doi.org/10.1161/01.RES.0000022200.71892.9F

Tokunaga C, Yoshino K and Yonezawa K (2004). mTOR integrates amino acid- and energy-sensing pathways. Biochem. Biophys. Res. Commun. 313: 443-446. http://dx.doi.org/10.1016/j.bbrc.2003.07.019

Um SH, D'Alessio D and Thomas G (2006). Nutrient overload, insulin resistance, and ribosomal protein S6 kinase 1, S6K1. Cell Metab. 3: 393-402. http://dx.doi.org/10.1016/j.cmet.2006.05.003

Wullschleger S, Loewith R and Hall MN (2006). TOR signaling in growth and metabolism. Cell 124: 471-484. http:// dx.doi.org/10.1016/j.cell.2006.01.016

Xu G, Li Y, An W, Li S, et al. (2009). Gastric mammalian target of rapamycin signaling regulates ghrelin production and food intake. Endocrinology 150: 3637-3644. http://dx.doi.org/10.1210/en.2009-0372

Xue B and Kahn BB (2006). AMPK integrates nutrient and hormonal signals to regulate food intake and energy balance through effects in the hypothalamus and peripheral tissues. J. Physiol. 574: 73-83. http://dx.doi.org/10.1113/ iphysiol.2006.113217

Yang Q and Guan KL (2007). Expanding mTOR signaling. Cell Res. 17: 666-681. http://dx.doi.org/10.1038/cr.2007.64

Yang X, Yang C, Farberman A, Rideout TC, et al. (2008). The mammalian target of rapamycin-signaling pathway in regulating metabolism and growth. J. Anim. Sci. 86 (E. Suppl): E36-E50.

Zhang SS, Liu MG, Kano A, Zhang C, et al. (2005). STAT3 activation in response to growth factors or cytokines participates in retina precursor proliferation. Exp. Eye Res. 81: 103-115. http://dx.doi.org/10.1016/j.exer.2005.01.016

\section{Supplementary material}

S1 Table. Primer pairs used to analyze gene expression by quantitative RT-PCR and the size of the product. 